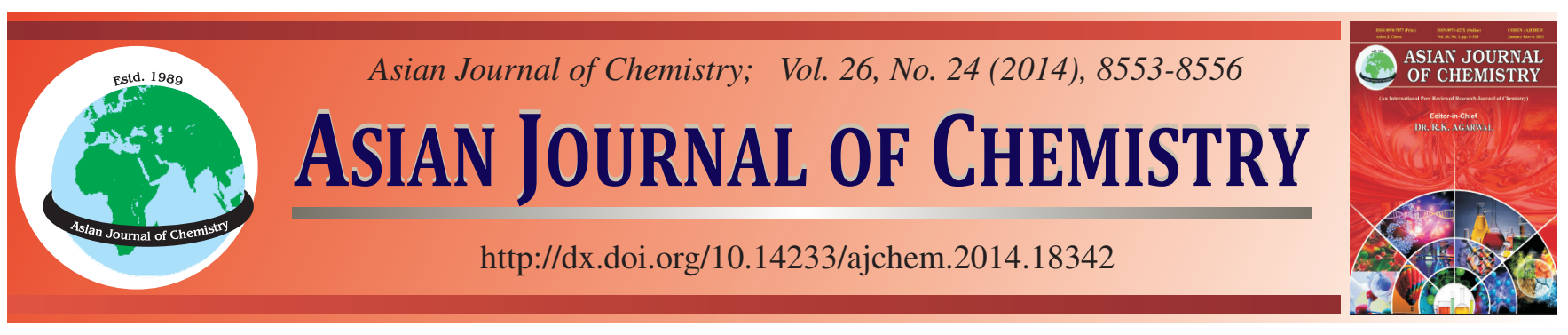

\title{
Preparation of Mesoporous Carbon Nitride Photocatalyst with Tunable Band Structure by Copolycondensation of Dicyandiamide and Urea
}

\author{
J. WAN ${ }^{1}$, S.Z. Hu ${ }^{2},{ }^{*}$, F.Y. $\mathrm{LI}^{2}$, Z.P. FAN ${ }^{2}$, G. $\mathrm{LU}^{3}$ and J. ZHANG ${ }^{4}$
}

${ }^{1}$ School of Experimental Education, Liaoning Shihua University, Fushun 113001, P.R. China

${ }^{2}$ Institute of Eco-environmental Sciences, Liaoning Shihua University, Fushun 113001, P.R. China

${ }^{3}$ School of Environmental and Biological Engineering, Liaoning Shihua University, Fushun 113001, P.R. China

${ }^{4}$ Liaoning Key Laboratory of Petroleum \& Chemical Industry, Liaoning Shihua University, Fushun 113001, PR China

*Corresponding author: Tel: +86 24 23847473; E-mail: jiewanlnpu@163.com

\begin{abstract}
A convenient template free method to prepare mesoporous $g-C_{3} \mathrm{~N}_{4}$ with a tunable band structure was reported by copolycondensation of dicyandiamide and urea. X-ray diffraction, $\mathrm{N}_{2}$ adsorption, elemental analysis, UV-visible spectroscopy, photoluminescence and X-ray photoelectron spectroscopy were used to characterize the prepared catalysts. The results indicated that copolycondensation of dicyandiamide and urea strongly influenced the polycondensation degree of prepared mesoporous $g-\mathrm{C}_{3} \mathrm{~N}_{4}$ materials, leading to the difference in structural property, optimal property and electronic structure. The activities of prepared catalysts were tested in the photocatalytic degradation of Rhodamine B under visible light. The mass fraction of urea plays the important role on the photocatalytic performance. The possible mechanism was proposed.
\end{abstract}

Keywords: $g-\mathrm{C}_{3} \mathrm{~N}_{4}$, Fe doping, Mesoporous material, Photocatalysis, Copolycondensation.

\section{INTRODUCTION}

Due to the incoming energy and environmental problems, photocatalysis is an attractive but very challenging process to convert solar energy into chemical energy. For the purpose of taking full advantages of solar energy, great efforts have been devoted to searching for suitable materials with visible light photocatalytic activities. Graphitic carbon nitride $\left(g-\mathrm{C}_{3} \mathrm{~N}_{4}\right)$, a typical metal-free polymeric semiconductor, has attracted a great deal of scientific interest due to its good chemical stability, appropriate band gap energy and unique electronic structure. The $g-\mathrm{C}_{3} \mathrm{~N}_{4}$ is considered to be the most stable allotrope in ambient conditions. The structure stability and redox ability of $g-\mathrm{C}_{3} \mathrm{~N}_{4}$ stimulate us to explore its application as a new metalfree photocatalyst that splits water to produce hydrogen or degrades organic pollutants under visible light. However, the efficiency of $g-\mathrm{C}_{3} \mathrm{~N}_{4}$ is still limited due to the high recombination rate of photogenerated electron-hole pairs and low surface area which is insufficient for visible-light utilization ${ }^{1}$. To resolve this problem, efforts have been made to improve the photocatalytic performance of $g-\mathrm{C}_{3} \mathrm{~N}_{4}$, such as metal and nonmetal doping ${ }^{2-8}$, protonating by strong acids ${ }^{9}$, designing composite with other semiconductors ${ }^{10-13}$ and preparation of porous $g-\mathrm{C}_{3} \mathrm{~N}_{4}{ }^{14-17}$.
In general, due to the high degree of polycondensation of monomers during the synthesis process, bulk $g-\mathrm{C}_{3} \mathrm{~N}_{4}$ exhibits a low surface area (usually less than $10 \mathrm{~m}^{2} \mathrm{~g}^{-1}$ ) without forming textured pores. It is known that large surface area is very important to heterogeneous photocatalysis process via offering more surface reactive sites, improving mass transfer and enhancing lightharvesting. Moreover, for the high surface area materials, the diffusion path of photoinduced electron-hole pair from the bulk to the surface is short, leading to the reduced recombination rate of electron-hole pair. Therefore, many efforts have been made to develop the $g-\mathrm{C}_{3} \mathrm{~N}_{4}$ with porous structure ${ }^{14-17}$. Vinu et $a^{14}$. reported the synthesis of mesoporous $g-\mathrm{C}_{3} \mathrm{~N}_{4}$ with a uniform pore diameter using SBA- 15 as a template. However, the carbon to nitrogen ratio of obtained material is high (3.3-4.5), making this material more like a nitrogen-doped carbon. Chen et al. ${ }^{15}$ has also applied a templating route to yield ordered mesoporous $g_{-}-\mathrm{C}_{3} \mathrm{~N}_{4}$ and studied its activity towards water splitting under visible light irradiation. Ansari et al. ${ }^{16}$ reported the synthesis of mesoporous $g-\mathrm{C}_{3} \mathrm{~N}_{4}$ materials using melamine as a precursor and nanosized silica as a hard template ${ }^{16}$. Xu et al. ${ }^{17}$ prepared mesostructured graphitic carbon nitride material using carbon tetrachloride and ethylenediamine as precursors and mesocellular silica foam (P123) as a hard template. The surface area of obtained materials were about $400 \mathrm{~m}^{2} \mathrm{~g}^{-1}$. 
Urea can be facilely thermal conversed into mesoporous $g-\mathrm{C}_{3} \mathrm{~N}_{4}$ without tailoring the reaction pressure and atmosphere $^{18}$. The drawback of this method is the low yield of mesoporous $g-\mathrm{C}_{3} \mathrm{~N}_{4}$, which may limits its practical application. In this work, a convenient template free method to prepare mesoporous $g-\mathrm{C}_{3} \mathrm{~N}_{4}$ with a tunable band structure was reported by copolycondensation of dicyandiamide and urea. Urea can decompose and generate gas bubble during the reaction and produce porous structure in $g-\mathrm{C}_{3} \mathrm{~N}_{4}$. The photocatalytic activities were evaluated in the photocatalytic degradation of Rhodamine-B under visible light.

\section{EXPERIMENTAL}

The mesoporous $g-\mathrm{C}_{3} \mathrm{~N}_{4}$ was prepared by pyrolysis of urea and dicyandiamide in air atmosphere. The typical preparation of mesoporous $g-\mathrm{C}_{3} \mathrm{~N}_{4}$ photocatalysts was as follows. The mixture of $3 \mathrm{~g}$ dicyandiamide and desired amount of urea was dissolved into $30 \mathrm{~mL}$ deionized water under stirring. The obtained solution was heated to $100{ }^{\circ} \mathrm{C}$ under stirring to remove the water. The solid product was dry at $100{ }^{\circ} \mathrm{C}$ in oven, followed by milling and annealing at $520^{\circ} \mathrm{C}$ for $2 \mathrm{~h}$ (at a rate of $5^{\circ} \mathrm{C}$ $\left.\min ^{-1}\right)$. The prepared catalyst was denoted as D-U (x), where $\mathrm{x}$ stands for the mass fraction of urea. For comparison, bulk $g$ $\mathrm{C}_{3} \mathrm{~N}_{4}$ was prepared following the same procedure as mentioned above but in the absence of urea. The obtained bulk $g-\mathrm{C}_{3} \mathrm{~N}_{4}$ was denoted as $\mathrm{D}$ (1.0).

$\mathrm{X}$-ray diffraction patterns of the prepared $\mathrm{TiO}_{2}$ samples were recorded on a Rigaku D/max-2400 instrument using $\mathrm{CuK}_{\alpha}$ radiation $(\lambda=1.54 \AA)$. UV-visible spectroscopy measurement was carried out on a JASCO V-550 model UV-visible spectrophotometer, using $\mathrm{BaSO}_{4}$ as the reflectance sample. Nitrogen adsorption was measured at $-196{ }^{\circ} \mathrm{C}$ on a Micromeritics 2010 analyzer. All the samples were degassed at $393 \mathrm{~K}$ before the measurement. BET surface area $\left(\mathrm{S}_{\mathrm{BET}}\right)$ was calculated according to the adsorption isotherm. X-ray photoelectron spectroscopy measurements were conducted on a Thermo Escalab 250 XPS system with $\mathrm{Al} \mathrm{K}_{\alpha}$ radiation as the exciting source. The binding energies were calibrated by referencing the $\mathrm{C} 1 \mathrm{~s}$ peak $(284.6 \mathrm{eV})$ to reduce the sample charge effect.

Rhodamine-B was selected as model compound to evaluate the photocatalytic performance of the prepared $g-\mathrm{C}_{3} \mathrm{~N}_{4}$ based catalysts in an aqueous solution under visible light irradiation. $0.05 \mathrm{~g}$ catalyst was dispersed in $200 \mathrm{~mL}$ aqueous solution of Rhodamine-B (10 ppm) in an ultrasound generator for $10 \mathrm{~min}$. The suspension was transferred into a self-designed glass reactor and stirred for $0.5 \mathrm{~h}$ in darkness to achieve the adsorption equilibrium. In the photoreaction under visible light irradiation, the suspension was exposed to a $250 \mathrm{~W}$ highpressure sodium lamp with main emission in the range of 400$800 \mathrm{~nm}$ and air was bubbled at $130 \mathrm{~mL} / \mathrm{min}$ through the solution. The UV light portion of sodium lamp was filtered by $0.5 \mathrm{M} \mathrm{NaNO}_{2}$ solution. All runs were conducted at ambient pressure and $30^{\circ} \mathrm{C}$. At given time intervals, $4 \mathrm{~mL}$ suspension was taken and immediately centrifuged to separate the liquid samples from the solid catalyst. The concentrations of Rhodamine-B before and after reaction were measured by means of a UV-visible spectrophotometer at a wavelength of $550 \mathrm{~nm}$.

\section{RESULTS AND DISCUSSION}

Fig. 1 shows the XRD patterns of synthesized bulk and mesoporous $g-\mathrm{C}_{3} \mathrm{~N}_{4}$ photocatalysts. The typical (002) interlayer-stacking peak at $27.3^{\circ}$ corresponds to an interlayer distance of $\mathrm{d}=0.32 \mathrm{~nm}$ for $g-\mathrm{C}_{3} \mathrm{~N}_{4}$, while the peak at $13.1^{\circ}$ represents in-plane structural packing motif (100) with a period of $0.675 \mathrm{~nm}^{19}$. It is noted that the D-U (x) showed an obviously decreased peak intensities with increasing the urea content, indicating that the crystal growth of graphitic carbon nitride is inhibited by introduction of urea. This is probably due to that urea decomposed at high temperature and generated gas bubble during the polycondensation process, thus inhibited the crystal growth of $g-\mathrm{C}_{3} \mathrm{~N}_{4}$. Besides, compared with bulk $g$ $\mathrm{C}_{3} \mathrm{~N}_{4} \mathrm{D}$ (1.0), a slight shift toward a higher $2 \theta$ value is observed for D-U (x) catalysts, indicating the interlayer distance of aromatic units is decreased ${ }^{20}$. The higher urea content, the higher $2 \theta$ value is observed. This is probably due to the difference in polycondensation degree. Niu et al. ${ }^{21}$ prepared nitrogen vacancy contained graphitic carbon nitride material at high calcination temperature and found the similar $2 \theta$ value shift phenomenon. They suggested that this phenomenon is due to the improved interlayer stacking order produced by the higher polycondensation degree caused by the high condensation temperature. In this investigation, the polycondensation degree of obtained $g-\mathrm{C}_{3} \mathrm{~N}_{4}$ could be enhanced by increasing the urea content.

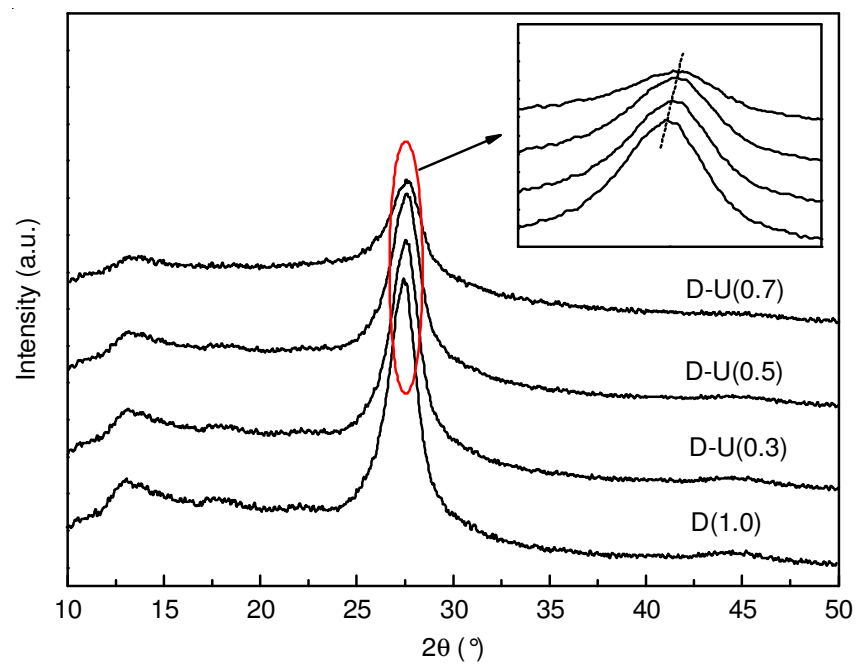

Fig. 1. XRD patterns of synthesized bulk and mesoporous $g-\mathrm{C}_{3} \mathrm{~N}_{4}$ photocatalysts

The light absorption property of as-prepared bulk and mesoporous $g-\mathrm{C}_{3} \mathrm{~N}_{4}$ photocatalysts is studied by UV-visible spectra and the results are shown in Fig. 2. Bulk $g-\mathrm{C}_{3} \mathrm{~N}_{4} \mathrm{D}$ (1.0) shows a typical semiconductor absorption. In case of the $\mathrm{D}-\mathrm{U}(\mathrm{x})$, the obviously improved absorptions in UV region as well as the red shifts of absorption band were observed with increasing the urea content. The band gap energy, which is calculated according to the method of Oregan and $\mathrm{Gratzel}^{22}$, is $2.65 \mathrm{eV}$ for $\mathrm{D}(1.0)$. This is consistent with the previous results $^{23,24}$. In the case of D-U (0.3), D-U (0.5) and D-U (0.7), this value decreased to $2.62,2.61$ and $2.59 \mathrm{eV}$. This is probably due to that the addition of urea improved the polyconden- 


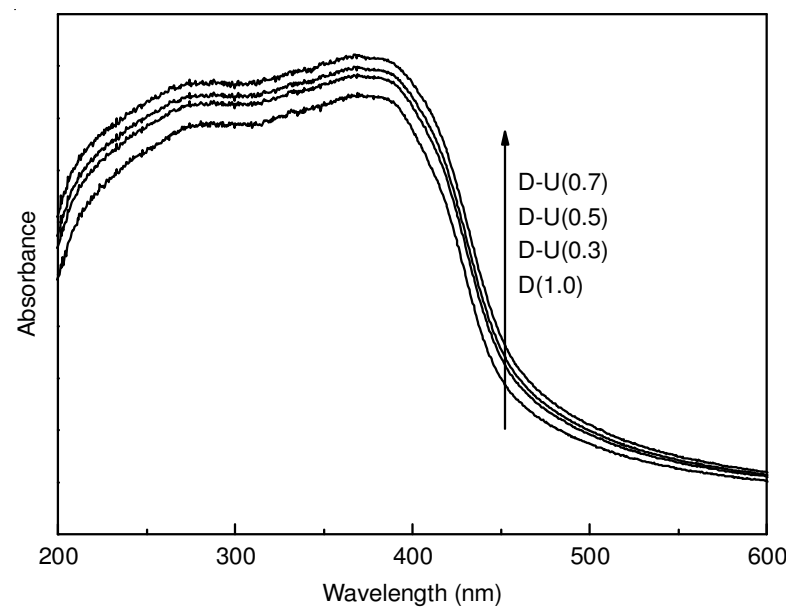

Fig. 2. UV-visible spectra of synthesized bulk and mesoporous $g-\mathrm{C}_{3} \mathrm{~N}_{4}$ photocatalysts

sation degree of prepared $g-\mathrm{C}_{3} \mathrm{~N}_{4}$ catalysts which influenced their band structure and density of state, leading to the change of optical property.

Fig. 3 shows the BET surface areas of prepared bulk and mesoporous $g-\mathrm{C}_{3} \mathrm{~N}_{4}$ photocatalysts. D (1.0) exhibited very small BET surface areas (less than $10 \mathrm{~m}^{2} \mathrm{~g}^{-1}$ ). This value increased with increasing the urea content. The BET surface area of D-U (0.7) reached $25.3 \mathrm{~m}^{2} \mathrm{~g}^{-1}, 3$ times higher than that of $\mathrm{D}$ (1.0). Obviously, the increasing urea may decompose into more bubbles during the thermal polymerization process, thus caused more porous structure, leading to the increased BET surface area. It is imagined that the BET surface area can be increased with further increasing the urea content. However, from the relationship of urea mass ratio and yield of mesoporous $g-\mathrm{C}_{3} \mathrm{~N}_{4}$ (Fig. 4), it is obviously that the $g-\mathrm{C}_{3} \mathrm{~N}_{4}$ yield decreased sharply to lower than $10 \%$ when the mass ratio of urea beyond 0.7 . Such low yield of $g-\mathrm{C}_{3} \mathrm{~N}_{4}$ limits its practical application. Therefore, it is deduced that the optimal mass ratio of urea is 0.7 .

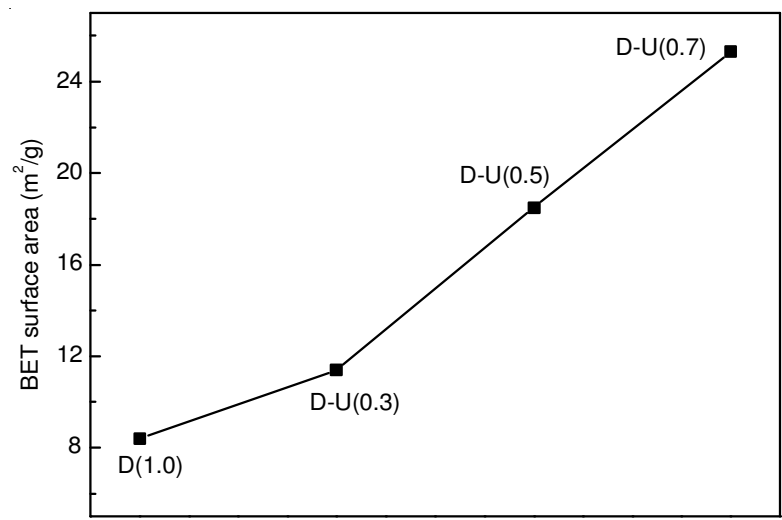

Fig. 3. BET surface areas of prepared bulk and mesoporous $g-\mathrm{C}_{3} \mathrm{~N}_{4}$ photocatalysts

In order to further investigate the effect of polycondensation degree on the relative positions of the conduction band minimum (CBM) and valence band maximum (VBM) of the $g-\mathrm{C}_{3} \mathrm{~N}_{4}$ catalysts, the valence band XPS was uesd to deter mine the electronic structure (Fig. 5). It is shown that the valence band maximum of $\mathrm{D}(1.0)$ located at $1.5 \mathrm{eV}$, which is similar

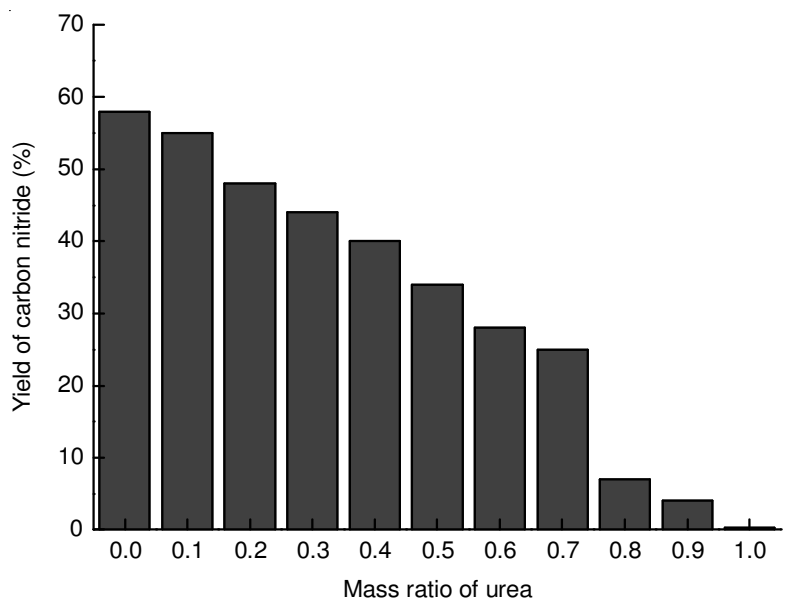

Fig. 4. Relationship of urea mass ratio and yield of mesoporous $g-\mathrm{C}_{3} \mathrm{~N}_{4}$

to the previous report. $1 \mathrm{D}-\mathrm{U}(0.7)$ exhibits the same valence band maximum potential as that of the $\mathrm{D}(1.0)$, indicating the polycondensation degree did not disturb the valence band maximum potential of $g-\mathrm{C}_{3} \mathrm{~N}_{4}$. In contrast, a change in the intrinsic electron distribution in the valence band maximum was achieved for D-U (0.7). Combined with the result of UVvisible spectra, the optical valence band maximum potential of D-U (0.7) should be shifted from -1.15 to $-1.09 \mathrm{eV}$. Since the interlayer distance of aromatic units is decreased by improving the polycondensation degree, the electron densities of carbon and nitrogen atoms could be increased. After that, the outer electrons of carbon and nitrogen atoms could be redistributed, which influenced the band structures and density of state of D-U (0.7), leading to the shift of valence band maximum potential. It is deduced that the band structure of $g-\mathrm{C}_{3} \mathrm{~N}_{4}$ can be tuned conveniently by changing the urea content.

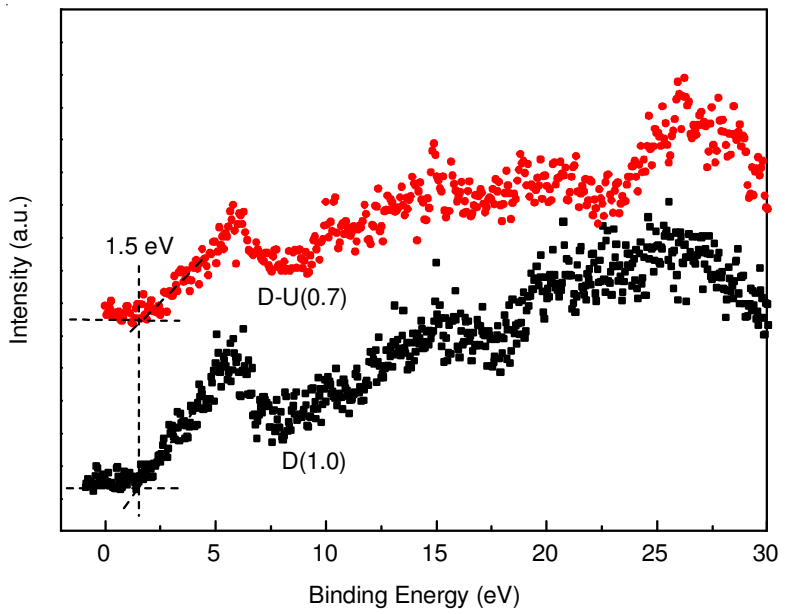

Fig. 5. Valence band XPS of prepared bulk and mesoporous $g-\mathrm{C}_{3} \mathrm{~N}_{4}$ photocatalysts

The photocatalytic performances of synthesized bulk and mesoporous $g-\mathrm{C}_{3} \mathrm{~N}_{4}$ photocatalysts in the degradation of Rhodamine-B under visible light irradiation were shown in Fig. 6a. Control experiment results indicated that the RhodamineB degradation performance can be ignored in the absence of either irradiation or photocatalyst, indicating that Rhodamine$\mathrm{B}$ was degraded via photocatalytic process. About $55 \%$ of Rhodamine-B was degraded over D (1.0) in $120 \mathrm{~min}$. The 
activities of D-U (x) were much higher than that of bulk D (1.0). Moreover, the activity increased with increasing the urea content. This should be due to the synergistic effect of decreased band gap energy, reduced recombination rate of photogenerated electrons/holes pairs and improved BET surface area.
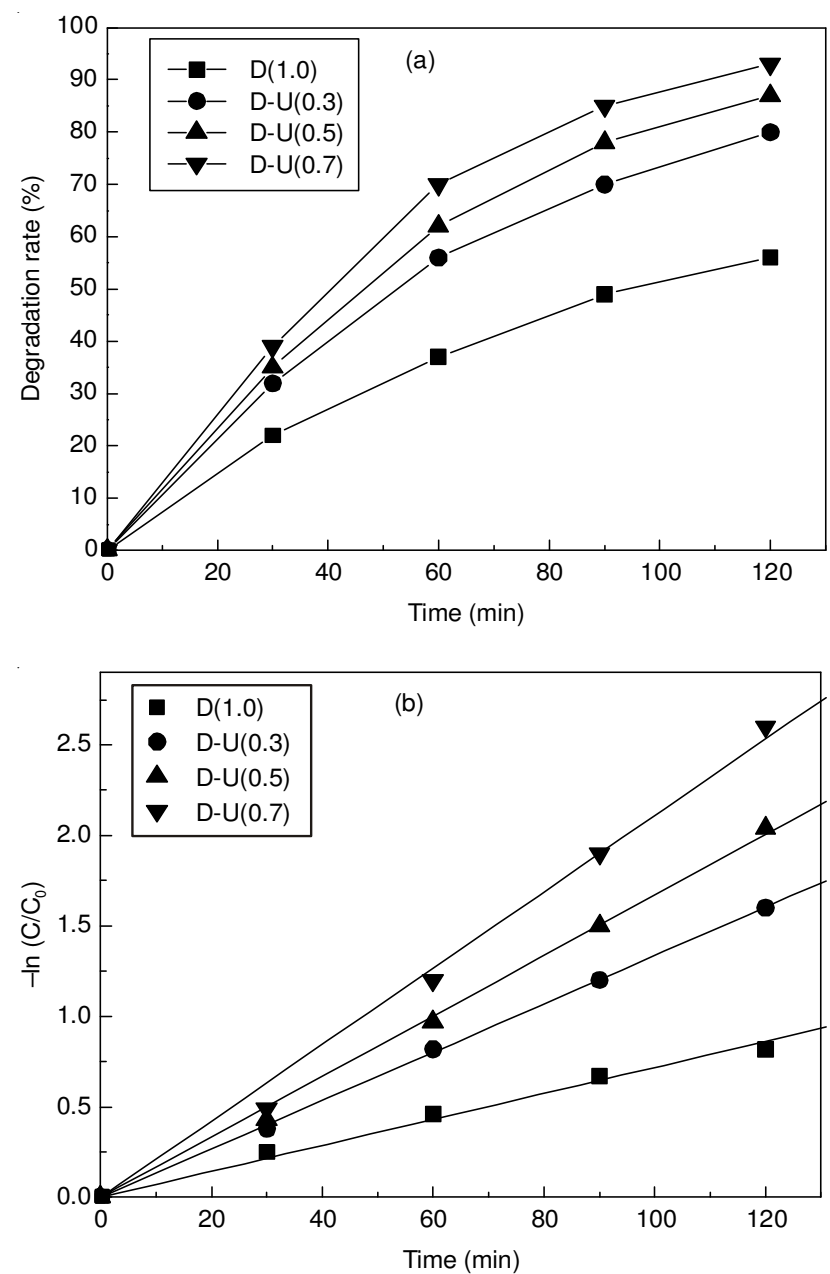

Fig. 6. Photocatalytic performances of bulk and mesoporous $g-\mathrm{C}_{3} \mathrm{~N}_{4}$ photocatalysts (a) and plot of $-\ln \left(C / \mathrm{C}_{0}\right)$ against reaction time $(\mathrm{b})$ in the degradation of Rhodamine-B under visible light irradiation

The reaction rate constant $\mathrm{k}$ was obtained by assuming that the reaction followed first order kinetics ${ }^{25}$. In a batch reactor, the performance equation is as follows: $-\ln \left(\mathrm{C} / \mathrm{C}_{0}\right)=$ kt where $\mathrm{C}_{0}$ and $\mathrm{C}$ represent the concentrations of Rhodamine$\mathrm{B}$ before and after photocatalytic degradation, respectively. If a linear relationship is established when $-\ln \left(\mathrm{C} / \mathrm{C}_{0}\right)$ is plotted against $t$ (reaction time), the rate constant $\mathrm{k}$ can be obtained from the slope of the line. Fig. $6 \mathrm{~b}$ displays the plot of $-\ln (\mathrm{C} /$ $\mathrm{C}_{0}$ ) against reaction time. The calculated results indicated that the rate constant $\mathrm{k}$ was $0.007,0.013,0.017$ and $0.021 \mathrm{~min}^{-1}$ for D (1.0), D-U (0.3), D-U (0.5) and D-U (0.7), respectively. $\mathrm{D}-\mathrm{U}(0.7)$ exhibited the highest rate constant which is 3 times higher than that of bulk $g-\mathrm{C}_{3} \mathrm{~N}_{4} \mathrm{D}$ (1.0). This increased photocatalytic performance should be attributed to the synergistic effect of decreased band gap energy which utilize visible light more efficiently, improved electrons-holes separation effi- ciency and improved BET surface area which can provide more surface reactive sites and adsorb more Rhodamine-B molecule on surface.

\section{Conclusion}

Mesoporous $g-\mathrm{C}_{3} \mathrm{~N}_{4}$ with a tunable band structure was prepared by a convenient template free method. The results indicated that copolycondensation of dicyandiamide and urea strongly influenced the polycondensation degree of prepared mesoporous $g-\mathrm{C}_{3} \mathrm{~N}_{4}$ materials, leading to the difference in structural property, optimal property and electronic structure. Optical valence band maximum potential of prepared mesoporous $g-\mathrm{C}_{3} \mathrm{~N}_{4}$ could be changed by altering the urea content. $\mathrm{D}-\mathrm{U}(0.7)$ exhibited the highest rate constant which is 3 times higher than that of bulk $g-\mathrm{C}_{3} \mathrm{~N}_{4} \mathrm{D}$ (1.0). This increased photocatalytic performance should be attributed to the synergistic effect of decreased band gap energy which utilize visible light more efficiently and improved BET surface area which can provide more surface reactive sites and adsorb more RhodamineB molecule on surface.

\section{REFERENCES}

1. X. Wang, K. Maeda, A. Thomas, K. Takanabe, G. Xin, J.M. Carlsson, K. Domen and M. Antonietti, Nat. Mater, 8, 76 (2009).

2. S.C. Yan, Z.S. Li and Z.G. Zou, Langmuir, 26, 3894 (2010).

3. Y.J. Zhang, T. Mori, J.H. Ye and M. Antonietti, J. Am. Chem. Soc., 132, 6294 (2010).

4. Y.Y. Bu, Z.Y. Chen and W.B. Li, Appl. Catal. B, 144, 622 (2014).

5. C. Chang, Y. Fu, M. Hu, C.Y. Wang, G.Q. Shan and L.Y. Zhu, Appl. Catal. B, 142-143, 553 (2013).

6. X.F. Chen, J.S. Zhang, X.Z. Fu, M. Antonietti and X.C. Wang, J. Am. Chem. Soc., 131, 11658 (2009).

7. X.C. Wang, X.F. Chen, A. Thomas, X.Z. Fu and M. Antonietti, $A d v$. Mater., 21, 1609 (2009).

8. G.G. Zhang, M.W. Zhang, X.X. Ye, X.Q. Qiu, S. Lin and X.C. Wang, Adv. Mater., 26, 805 (2014).

9. Y.J. Zhang, A. Thomas, M. Antonietti and X.C. Wang, J. Am. Chem. Soc., 131, 50 (2009).

10. C.S. Pan, J. Xu, Y.J. Wang, D. Li and Y.F. Zhu, Adv. Funct. Mater., 22, 1518 (2012).

11. L.Y. Huang, H. Xu, Y.P. Li, H.M. Li, X.N. Cheng, J.X. Xia, Y.Q. Xu and G.B. Cai, Dalton Trans., 42, 8606 (2013).

12. K. Sridharan, E. Jang and T.J. Park, Appl. Catal. B, 142-143, 718 (2013).

13. S.Q. Zhang, Y.X. Yang, Y.N. Guo, W. Guo, M. Wang, Y.H. Guo and M.X. Huo, J. Hazard. Mater., 261, 235 (2013).

14. A. Vinu, K. Ariga, T. Mori, T. Nakanishi, S. Hishita, D. Golberg and Y. Bando, Adv. Mater., 17, 1648 (2005).

15. X. Chen, Y.S. Jun, K. Takanabe, K. Maeda, K. Domen, X.Z. Fu, M. Antonietti and X.C. Wang, Chem. Mater., 21, 4093 (2009).

16. M.B. Ansari, B.H. Min, Y.H. Mo and S.E. Park, Green Chem., 13, 1416 (2011).

17. J. Xu, K.Z. Long, T. Chen, B. Xue, Y.X. Li and Y. Cao, Catal. Sci. Technol., 3, 3192 (2013).

18. S. Min and G. Lu, J. Phys. Chem. C, 116, 19644 (2012).

19. Y. Wang, X.C. Wang and M. Antonietti, Angew. Chem. Int. Ed., 51, 68 (2012).

20. F. Chang, Y.C. Xie, C.L. Li, J. Chen, J.R. Luo, X.F. Hu and J.W. Shen, Appl. Surf. Sci., 280, 967 (2013).

21. P. Niu, G. Liu and H.M. Cheng, J. Phys. Chem. C, 116, 11013 (2012).

22. B. Oregan and M. Gratzel, Nature, 353, 737 (1991).

23. H.J. Yan and H.X. Yang, J. Alloys Compd., 509, L26 (2011).

24. X.C. Wang, S. Blechert and M. Antonietti, ACS Catal., 2, 1596 (2012).

25. S.Z. Hu, L. Ma, J.G. You, F.Y. Li, Z.P. Fan, F. Wang, D. Liu and J.Z. Gui, RSC Adv., 4, 21657 (2014) 